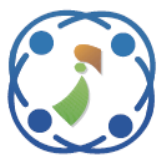

\title{
Business Process Models Complexity Growth Analysis based on Scheduling Generated by Timetabling of Courses
}

\author{
Muhammad Ainul Yaqin ${ }^{1,2 *}$ \\ Riyanarto Sarno ${ }^{1}$ \\ Siti Rochimah ${ }^{1}$ \\ ${ }^{1}$ Department of Informatics, Institut Teknologi Sepuluh Nopember Surabaya, Indonesia \\ ${ }^{2}$ Department of Informatics, Universitas Islam Negeri Maulana Malik Ibrahim Malang, Indonesia \\ * Corresponding author's Email: riyanarto@if.its.ac.id
}

\begin{abstract}
Business process models can represent course schedules. Every business process model has complexity. The greater the number of courses and the number of study groups, the more complex the business process model. The rate of increase in the complexity of the business process model is referred to as growth. The growth in the business process model complexity helps estimate business processes resource requirements at a certain complexity level. Therefore the equation for the growth of the complexity of the business process model needs to be formulated. The equation for the growth in the business process model complexity is obtained through several stages, namely developing a course schedule using the aSc TimeTables software. The order of the scheduling results is formatted as an event $\log$. The event $\log$ is used as material in the mining process using the inductive mining algorithm to get a business process model represented using the Business Process Modeling Notation (BPMN). The complexity of the business process model is calculated using the Yaqin complexity formula. The equation for the growth function for the complexity of the business process model as a function of the number of study groups is obtained through logistic regression. Logistic regression is based on a logistic equation with 3 parameters, 4 parameters, and 5 parameters. Based on the three types of logistic equations regression results, we find that the logistic equation with 5 parameters has the highest average value of $\mathrm{R}^{2}$, namely 0.9698 . Meanwhile, the equations for the growth of the business process model complexity are a function of the number of courses through power regression. The equations obtained through power regression have an average value of $R^{2}=0.9549$. In this study, regression is carried out separately between the growth function as the number of study groups with the growth function as a function of the number of courses. This research novelty lies in using the number of study groups and the number of courses to measure the growth in the business process model complexity.
\end{abstract}

Keywords: Growth, Complexity, Business process model, BPMN, Courses schedule.

\section{Nomenclature}

$\begin{array}{cl}Y C & \text { Yaqin complexity } \\ N S & \text { Nodes size } \\ A s & \text { Arc size } \\ C_{A N D} & \text { Complexity of AND branching } \\ C_{X O R} & \text { Complexity of XOR branching } \\ C_{O R} & \text { Complexity of OR branching } \\ C_{c y c} & \text { Complexity of cyclic } \\ C_{D} & \text { Complexity of depth } \\ y & \text { Value on y-axis } \\ x & \text { Value on X-axis }\end{array}$

$\begin{array}{ll}a & \text { Lower asymptote } \\ b & \text { Slope variable } \\ c & \text { Inflection point } \\ d & \text { Upper asymptote } \\ f & \text { Asymmetry variable } \\ g & \text { Rate of increase in value } \\ h & \text { Direction facing curve }\end{array}$

\section{Introduction}

School is a tiered and continuous education unit that organizes learning activities [1]. Students receive learning services at school to gain competencecompetencies implementing in the curriculum. The 
curriculum is a set of learning plans used as guidelines for the implementation of learning [1]. The curriculum consists of several courses. Learning is carried out on a scheduled basis using available resources.

Nassar and Hegab, in 2006 have surveyed various ways to measure schedule complexity [2]. In 2020 Morcov, Pintelon, and Kusters also surveyed the measurement of project complexity, in which the schedule is also included [3]. The measurement of schedule complexity that researchers have carried out is not comprehensive and sensitive to small changes in the schedule. Therefore, in this study, the implementation of the course schedule is represented through BPMN. BPMN complexity can be measured using Yaqin Complexity, which is more comprehensive and sensitive to small changes [4]. The learning business process model becomes increasingly complex along with the increasing number of study groups and the increasing number of courses, so it can be said that the complexity of the learning business process model is scalable [5]. The consequence of the increasing business process model complexity is the increase in the business process resources requirement. Besides, suppose an information system will serve the business process. In that case, the business process model complexity can determine the information system configuration that will serve it. Therefore, to anticipate the consequences of increasing the complexity of business processes, the rate of increasing complexity must be known.

The problem formulation is how to obtain the growth equation for the complexity of the learning business process model as a function of the number of study groups and the number of courses. This study aims to obtain the equation for the business process model growth based on the course schedule. The benefit of the business process model complexity's growth function can estimate the business process resource requirements at a certain complexity level. The novelty proposed in this study is the measurement of the complexity of the business process model based on the number of courses as a representation of the number of activities in the business process model and the number of study groups as a representation of the number of cases.

The rate of increase in the complexity of the business process model is represented by the growth function of the business process model complexity. The business process model is part of an organization. Every organization has an organizational structure. Each section in the organizational structure has a job description. Each job description can have several standard operating procedures represented in the form of a business process model. The variables used to measure growth have been proposed by many researchers, including Weinzimmer, Nystrom, and Freeman in 1998, who surveyed the methods used to measure organizational growth [6]. A survey conducted by Adomako and Mole in 2018 confirmed that the variables used in the Weinzimmer, Nystrom, and Freeman surveys are still relevant for measuring organizational growth [7]. In this paper, we use different variables from previous studies, namely the number of study groups and the number of courses as variables to measure the growth in the complexity of the business process model. The complexity of business processes is one indicator of organizational growth, as stated by Vaz in 2021, where organizational structure is one factor that determines the growth of an organization [8]. This study is the first to propose using the number of study groups and the number of courses as variables in measuring the growth in complexity of business process models.

There are several kinds of regressions used to obtain the growth function. Michael J. Panik describes linear growth curve modeling, logarithmic reciprocity, logistic, Gompertz, Weibull, negative exponential, von Bertalanffy, Log-logistics, Brody growth model, Janoschek, Lundqvist-Korf, Hossfeld, Stannard, Schnute, Morgan-Mercer-Flodin, McDillAmateis, and Sloboda [9]. In this paper, we use a logistic growth model with a variation of 3 parameters, 4 parameters, and 5 parameters to obtain the growth function as a function of the number of study groups. Besides, we also obtain the function of growth as a function of the number of courses. The regression used for this purpose is power regression.

This research is part of a broader scope, namely the development of enterprise architecture growth metrics. Enterprise architecture represents an organization in terms of business architecture, information systems architecture, and technology architecture. Thus when an organization grows, the enterprise architecture also experiences growth. In this study, growth is measured based on the complexity of the business process model. This research is a continuation of the business process models complexity metrics development [4]. Complexity metrics of several business process models are used to obtain an equation for the growth in complexity of business process models.

This paper is organized as follows, background, problem formulation, related research, and contributions are presented in section 1. Section 2 explains the theories related to this research, namely about Scheduling, Event Log, Process Mining, Yaqin Complexity, Logistic Regression and Power Regression, and Previous Work of this research. 
Section 3 describes the methods and stages used to discover growth function of business process model complexity metrics. Then in section 4 , we explain the experimental results and their discussion. Section 5 describes the conclusions of this study.

\section{Theory}

\subsection{Scheduling}

According to the Cambridge dictionary, the schedule definition is a list of planned activities at certain times [10]. The definition of scheduling by Wren in 1995 is divided into several terms, namely scheduling, timetabling, sequencing, and rostering. The scheduling definition is the allocation of resources that are affected by several constraints on objects placed in space-time in such a way as to minimize the total cost of the several sets of resources used. The timetabling definition is the allocation of resources that is influenced by several constraints on objects placed in space-time in such a way as to meet the desired objectives as closely as possible. The sequencing definition is a construct influenced by several constraints from the sequence of activities or objects in several representations of the solution. The rostering definition is the placement influenced by several resource constraints into slots in a pattern [11].

Timetabling has been done in various ways. Schaerf, in 1999 identified the problems that occurred in timetabling [12]. Schaerf classified the problem into 3, namely, school timetabling, course timetabling, and examination timetabling. School timetabling solves class scheduling problems in one week, eliminating teacher meetings in more than one class at the same time. Course timetabling solves the problem of scheduling lecturers from a set of courses in one week, minimizing the overlap of course lecturers with the same students. Examination timetabling solves the problem of scheduling course exams, eliminates overlap of course exams that have the same students, and distributes as many exams as possible. In 2021, Tan, Goh, Kendall, and Sabar updated the Schaerf survey. They managed to identify 22 scheduling constraints and 14 methods to solve scheduling problems [13]. The methods used to automate timetabling are presented in Table 1.

This study uses a novel in-house developed algorithm embedded in the aSc TimeTables application to the course schedule [14].

\subsection{Event log}

The event log records a collection of cases
Table 1. Automated timetabling methods

\begin{tabular}{|c|c|c|c|}
\hline Methods & \begin{tabular}{|c|} 
School \\
timetabling
\end{tabular} & \begin{tabular}{|c|}
$\begin{array}{c}\text { Course } \\
\text { timetabling }\end{array}$ \\
\end{tabular} & \begin{tabular}{|c|} 
Examination \\
timetabling
\end{tabular} \\
\hline $\begin{array}{l}\text { Direct } \\
\text { Heuristic }\end{array}$ & $\checkmark$ & & $\checkmark$ \\
\hline $\begin{array}{l}\text { Reduction To } \\
\text { Graph } \\
\text { Coloring }\end{array}$ & $\checkmark$ & $\checkmark$ & $\checkmark$ \\
\hline $\begin{array}{l}\text { Network Flow } \\
\text { Techniques }\end{array}$ & $\checkmark$ & $\checkmark$ & \\
\hline $\begin{array}{l}\text { Genetic } \\
\text { Algorithms }\end{array}$ & $\checkmark$ & $\checkmark$ & $\checkmark$ \\
\hline $\begin{array}{l}\text { Simulated } \\
\text { Annealing }\end{array}$ & $\checkmark$ & $\checkmark$ & $\checkmark$ \\
\hline $\begin{array}{l}\text { Logic } \\
\text { Programming } \\
\text { Approach }\end{array}$ & $\checkmark$ & $\checkmark$ & \\
\hline $\begin{array}{l}\text { Constraint } \\
\text { Based } \\
\text { Approach }\end{array}$ & $\checkmark$ & & \\
\hline Tabu Search & $\checkmark$ & $\checkmark$ & \\
\hline \begin{tabular}{|l|} 
Integer Linear \\
Programming
\end{tabular} & $\checkmark$ & $\checkmark$ & \\
\hline $\begin{array}{l}\text { Rule-Based } \\
\text { Approach }\end{array}$ & & $\checkmark$ & \\
\hline $\begin{array}{l}\text { Constraint } \\
\text { Logic Based } \\
\text { Approach }\end{array}$ & $\checkmark$ & $\checkmark$ & \\
\hline $\begin{array}{l}\text { Graph } \\
\text { Coloring }\end{array}$ & & $\checkmark$ & \\
\hline $\begin{array}{l}\text { Set } \\
\text { Partitioning }\end{array}$ & & $\checkmark$ & \\
\hline $\begin{array}{l}\text { Lagrangian } \\
\text { Relaxation } \\
\text { Technique }\end{array}$ & & & $\checkmark$ \\
\hline $\begin{array}{l}\text { Novel In- } \\
\text { House } \\
\text { Developed }\end{array}$ & $\checkmark$ & $\checkmark$ & $\checkmark$ \\
\hline $\begin{array}{l}\text { Integer } \\
\text { Programming }\end{array}$ & $\checkmark$ & & \\
\hline $\begin{array}{l}\text { Adaptive } \\
\text { Large } \\
\text { Neighborhood } \\
\text { Search }\end{array}$ & $\checkmark$ & & \\
\hline $\begin{array}{l}\text { Variable } \\
\text { Neighborhood } \\
\text { Search }\end{array}$ & $\checkmark$ & & \\
\hline Particle Swarm & $\checkmark$ & & \\
\hline $\begin{array}{l}\text { Cyclic } \\
\text { Transfer } \\
\text { Algorithm } \\
\end{array}$ & $\checkmark$ & & \\
\hline $\begin{array}{l}\text { Graph } \\
\text { Coloring }\end{array}$ & $\checkmark$ & & \\
\hline $\begin{array}{l}\text { Parallel Local } \\
\text { Search }\end{array}$ & $\checkmark$ & & \\
\hline Tabu Search & $\checkmark$ & & \\
\hline
\end{tabular}

consisting of a series of events with a specific 
sequence [15]. The event log must have at least the case identity, event identity, event name, event start time timestamp, and event end timestamp. For other purposes, the event resources can be added, the event duration, and the event actors.

The event $\log$ is used as the primary data for the mining process. To be used in the mining process, the event log must be formatted in such away. Commonly used event log formats are Comma Separated Values (CSV), Mining eXtensible Markup Language (MXML), and eXtensible Event Stream (XES) [16]. In this study, we use the CSV format to represent the learning business process event log.

\subsection{Process mining}

Process mining is a discipline that deals with discovering, monitoring, and improving processes by extracting knowledge from event log information systems [17]. Process discovery is a series of activities that are used to get a process model automatically. Some algorithms for obtaining business process models are alpha, alpha + , alpha ++ , alpha \#, alpha $\$$, heuristic miner, fuzzy miner, inductive miner, hybrid integer linear programming miner, structured miner, evolutionary tree miner, BPMN miner, and causal net miner [18, 19].

This study uses the inductive miner algorithm to obtain a business process model from a set of event logs. The inductive mining algorithm is built from two stages, namely Eq. (1) splitting the log into several sub-processes so that it cannot be broken down anymore; Eq. (2) determine the branching in each sub-process $[15,20]$.

\subsection{Yaqin complexity}

The complexity of the business process model represents a problem state that requires a solution [21]. The business process model complexity can be measured in various ways and metrics using the Yaqin complexity formula. In this paper, we use Yaqin complexity because it is more comprehensive and more sensitive to small changes in the structure of the business process model compared to the Cognitive Activity Depth Arc Control flow (CADAC) formula proposed by Coskun, Cyclomatic Complexity proposed by McCabe, Control Flow Complexity proposed by Cardoso, and Cognitive Weight proposed by Gruhn and Laue [4]. The Yaqin complexity formula is presented in Eq. (1)

$$
Y C=N s+A s+C_{A N D}+C_{X O R}+C_{O R}+C_{C Y C}+C_{D}
$$

\subsection{Logistic regression and power regression}

Regression is a statistical process that is useful for estimating the relationship between the dependent variable and one or more independent variables. The relationship between the dependent variable and the independent variable is represented in an equation determined according to the dependent variable and the independent variable value data distribution pattern. The equations generated by regression can be either linear equations or non-linear equations represented by a curve. Linear equations are represented by curves that form straight lines, while non-linear equations are represented by curves that form lines that are not straight.

Logistic regression is a form of non-linear regression. The logistic regression follows the shape of the sigmoid curve as presented in Eq. (2) [9].

$$
y=\frac{d}{1+c \cdot e^{b \cdot x}}
$$

Logistic regression also has two other forms of the equation, namely the 4 parameters logistic regression equation (4PL), which is presented in Eq. (3), and the 5 parameters logistic regression equation (5PL), which is presented in Eq. (4) [22].

$$
\begin{aligned}
& y=d+\frac{a-d}{1+\left(\frac{x}{c}\right)^{b}} \\
& y=d+\frac{a-d}{\left[1+\left(\frac{x}{c}\right)^{b}\right]^{f}}
\end{aligned}
$$

Another form of non-linear regression is power regression. The power regression is presented in Eq. (5) [23].

$$
y=g x^{h}
$$

\subsection{Previous work}

This research is a series of previous research. The first study discusses the formulation of the scalability of the business process model. The Business process model scalability is defined as a scale comparison between two business process models with similarities [5]. The scalability formula is a static representation of growth because it only compares the scale between the two business process models, in contrast to this study, representing dynamic growth. Dynamic growth is defined as a continuous change in complexity represented by the growth function.

The next series of research discusses the formulation of business process model complexity 
metrics. The complexity metrics proposed by many researchers are less comprehensive and sensitive to minor changes to the business process model. The schedule complexity metric surveyed by Nassar and Hegab involves the number of activities, the duration of the activity, the number of resources used in an activity, the number of predecessors, the number of successors, and their number of successors derivatives [2]. Therefore, a complexity metric formulation that is more comprehensive and sensitive to small changes is proposed and named Yaqin Complexity [4]. Yaqin Complexity involves more variables to measure the complexity of the business process model, namely the number of nodes, the number of arcs, the complexity of branching, the complexity of cyclic, and the depth complexity. Branching complexity involves the type of branching and the number of branches. Cyclic complexity involves the number of activities involved and the diameter of the business process model. Depth complexity involves the level of depth and amount of activity. Yaqin complexity is proven to be more comprehensive and sensitive than Cognitive Activity Depth Arc Control flow (CADAC), Cyclomatic Complexity, Control Flow Complexity, Cognitive Complexity, and Scale [4]. In this study, Yaqin Complexity is used to measure the complexity of the business process model. The complexity of several business process models is measured by varying degrees of complexity based on the number of cases and activities obtained from a case study.

Many kinds of research on organizational growth have been carried out. The variables used to measure the growth vary. In 1998, Weinzimmer, Nystorm, and Freeman surveyed to identify and describe methods and variables for measuring organizational growth. The result is that 35 growth measurement methods are identified and described, consisting of 28 methods based on total sales, seven methods based on the number of employees, and the rest based on market share, dividends, income, and customers [6]. In 2018, Adomako and Mole updated the survey and confirmed that these variables are still relevant for measuring organizational growth [7]. The growth function formulations surveyed all use time and these variables as independent variables. This study uses the number of courses and the number of study groups as independent variables to obtain a complexity metric in a complexity growth function.

\section{Methods}

The research procedure used in this paper as follows :
- Data collection. The data required are (1) a list of courses and their credits in one week; (2) The number of study groups scheduled; (3) The number of resources used for the learning process, namely the number of teachers and classrooms as a limitation and rules for scheduling.

- Development of a lesson schedule for one week using the aSc TimeTables application. This scheduling applies several rules and assumptions in scheduling it.

- Creating event logs based on the developed schedule.

- The discovery of business process models with BPMN notation. The business process model is obtained through process mining using the inductive miner algorithm.

- The calculation of the complexity metric of the business process model obtained from process mining using the Yaqin Complexity formula.

- Averaging metric complexity of business process models for each variation of the number of classrooms.

- Regression metric complexity of the business process model uses logistic regression based on Eqs. (2), (3), and (4) to obtain the growth function for the complexity of the business process model as a function of the number of study groups. Regression is performed with the number of study groups on the $\mathrm{x}$-axis and the complexity metric on the y-axis. This regression result is the growth function of the business process model complexity metric as a function of the number of study groups.

- Power regression based on the Eq. (5) in the metric complexity of business process models to obtain growth function model complexity of business processes as a function of the number of courses. Regression is performed with the number of courses on the $\mathrm{x}$-axis and the complexity metric on the y-axis. The result of this regression is a function of the growth in the business process model complexity as a function of the number of courses.

\subsection{Data collection}

The first stage in this research is data collection. The data required are (1) List of courses and their credit in one week. In this study we used $8,10,12$, and 17 courses in one week. List of courses along with their credits is presented in Table 2; (2) The number of study groups scheduled varies from 3 study groups to 27 study groups; (3) the number of resources used for the learning process. Each teacher teaches one course. The number of teachers is 


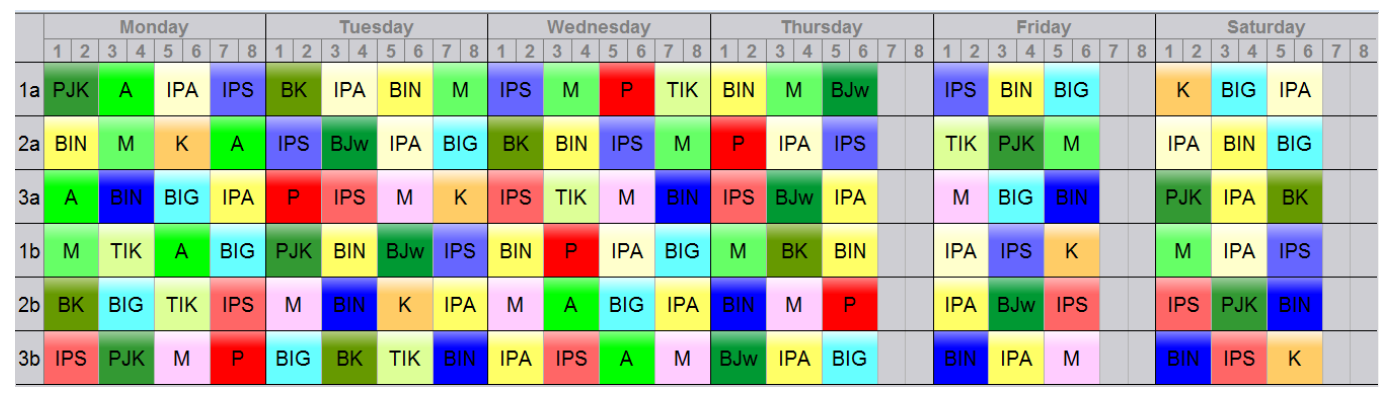

Figure. 1 Example of courses time tabling for 12 courses and 6 study group

Table 2. Courses and credits

\begin{tabular}{|c|c|c|c|c|c|}
\hline \multirow[b]{2}{*}{ Courses } & \multirow{2}{*}{$\begin{array}{l}\text { Course } \\
\text { Codes }\end{array}$} & \multicolumn{4}{|c|}{ Credits/week } \\
\hline & & $\begin{array}{c}8 \\
\text { Courses }\end{array}$ & \begin{tabular}{|c|}
10 \\
Courses
\end{tabular} & \begin{tabular}{|c|}
12 \\
Courses
\end{tabular} & $\begin{array}{c}17 \\
\text { Courses }\end{array}$ \\
\hline $\begin{array}{c}\text { Civic } \\
\text { education }\end{array}$ & $\mathrm{P}$ & 6 & 4 & 2 & 2 \\
\hline $\begin{array}{l}\text { Religious } \\
\text { education }\end{array}$ & A & 2 & 2 & 2 & $\mathrm{n} / \mathrm{a}$ \\
\hline Indonesian & BIN & 10 & 6 & 6 & 6 \\
\hline Mathematics & $\mathrm{M}$ & 6 & 6 & 6 & 6 \\
\hline Natural science & IPA & $\mathrm{n} / \mathrm{a}$ & 4 & 6 & 6 \\
\hline Social science & IPS & $\mathrm{n} / \mathrm{a}$ & 4 & 6 & 4 \\
\hline Art & $\mathrm{K}$ & 2 & 2 & 2 & 2 \\
\hline $\begin{array}{l}\text { Health and } \\
\text { physical } \\
\text { education }\end{array}$ & PJK & 2 & 2 & 2 & 2 \\
\hline English & BIG & $\mathrm{n} / \mathrm{a}$ & $\mathrm{n} / \mathrm{a}$ & 4 & 4 \\
\hline Javanese & $\mathrm{BJw}$ & 2 & 2 & 2 & 2 \\
\hline $\begin{array}{l}\text { Information } \\
\text { technology }\end{array}$ & TIK & $\mathrm{n} / \mathrm{a}$ & $\mathrm{n} / \mathrm{a}$ & 2 & 2 \\
\hline Counseling & BK & $\mathrm{n} / \mathrm{a}$ & $\mathrm{n} / \mathrm{a}$ & 2 & 2 \\
\hline $\begin{array}{c}\text { Al-Quran and } \\
\text { Hadith }\end{array}$ & $\mathrm{AH}$ & $\mathrm{n} / \mathrm{a}$ & $\mathrm{n} / \mathrm{a}$ & $\mathrm{n} / \mathrm{a}$ & 2 \\
\hline $\begin{array}{l}\text { Aqidah and } \\
\text { Akhlaq }\end{array}$ & AA & $\mathrm{n} / \mathrm{a}$ & $\mathrm{n} / \mathrm{a}$ & $\mathrm{n} / \mathrm{a}$ & 2 \\
\hline Fiqh & $\mathrm{F}$ & $\mathrm{n} / \mathrm{a}$ & $\mathrm{n} / \mathrm{a}$ & $\mathrm{n} / \mathrm{a}$ & 2 \\
\hline $\begin{array}{l}\text { History of } \\
\text { Islam }\end{array}$ & SKI & $\mathrm{n} / \mathrm{a}$ & $\mathrm{n} / \mathrm{a}$ & $\mathrm{n} / \mathrm{a}$ & 2 \\
\hline Arabic & BA & $\mathrm{n} / \mathrm{a}$ & $\mathrm{n} / \mathrm{a}$ & $\mathrm{n} / \mathrm{a}$ & 4 \\
\hline Crafting & $\mathrm{Pk}$ & 2 & 2 & $\mathrm{n} / \mathrm{a}$ & 2 \\
\hline
\end{tabular}

Table 3. Event $\log$ for study group $1 \mathrm{a}$ and $1 \mathrm{~b}$

\begin{tabular}{|c|c|l|}
\hline $\begin{array}{c}\text { Study } \\
\text { Group }\end{array}$ & Case & \multicolumn{1}{c|}{ Event Log } \\
\hline $1 \mathrm{a}$ & 1 & $\begin{array}{l}\text { PJK-A-IPA-IPS-BK-IPA-BIN-M- } \\
\text { IPS-M-P-TIK-BIN-M-BJw-IPS-BIN- } \\
\text { BIG-K-BIG-IPA }\end{array}$ \\
\hline $1 \mathrm{~b}$ & 2 & $\begin{array}{l}\text { M-TIK-A-BIG-PJK-BIN-BJw-IPS- } \\
\text { BIN-P-IPA-BIG-M-BK-BIN-IPA- } \\
\text { IPS-K-M-IPA-IPS }\end{array}$ \\
\hline
\end{tabular}

obtained based on the rule that each teacher gets a maximum workload of 24 credit a week. The number of classrooms is the same as the number of study groups.

\subsection{Schedule development}

The second stage is developing a schedule. This schedule development uses the aSc TimeTables application, which can be downloaded at https://www.asctimetables.com. The scheduling process applies the following rules: (1) the time slice for each course is 2 credits; (2) no one course is scheduled more than once a day; (3) scheduling using 6 days of study; (4) more class hours are scheduled at the beginning of the week than at the weekend; (5) PJK must end at the maximum during the 4 th lesson hour. The schedule varies for $3,6,9,12,15,18,21$, 24 , and 27 study groups. An example of scheduling results for 12 courses and 6 study groups using aSc TimeTables is presented in Figure. 1.

\subsection{Event log generation}

The third stage generates the event log. The event $\log$ is recorded based on the order of execution of the courses in each study group. We consider the implementation of learning in each study group as a case. Each course is represented as an activity in the event log. Event log logging for study group 1a and $1 \mathrm{~b}$ in Fig. 1 presented on Table 3. Class 2 and class 3 event $\log$ s are recorded in separate files because we want to get a different business process model through process mining. Furthermore, event log recording is carried out for all study groups, stored in one file. Event log recording is carried out for all the learning outcomes in each study group in each class. We log the event log using a spreadsheet application and save it in .csv format.

\subsection{The discovery of the business process model}

The fourth stage is to find a business process model for each schedule variation through process mining. We do process mining using the ProM software, which can be downloaded at http://www.processmining.org. The algorithm used in process mining is Inductive Miner. The event $\operatorname{logs}$ in .csv format are imported into ProM for conversion to xes format. Then the xes file is processed mining using the Inductive Miner algorithm. The result of this mining process is a business process model with BPMN notation. The business process model results from the mining 


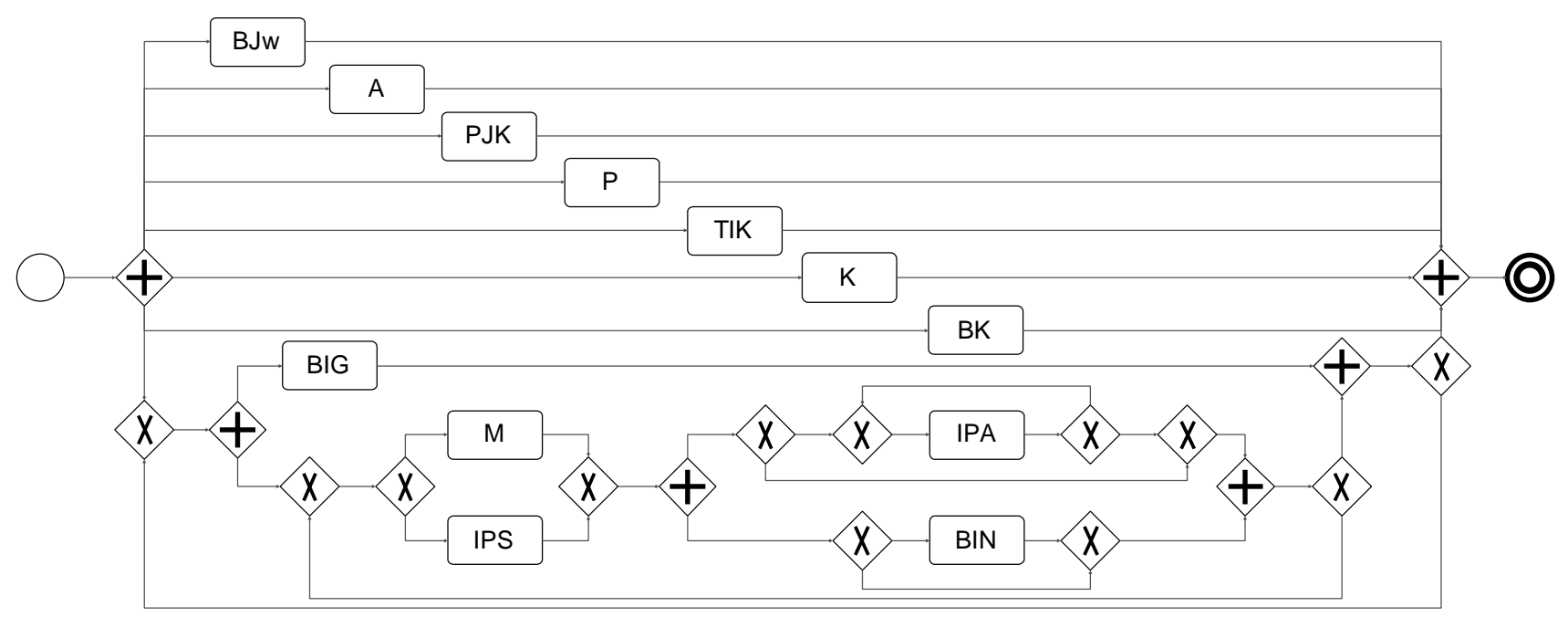

Figure. 2 Business process model as result of process mining for 12 courses and 6 study group

Table 4. Business process models complexity calculation results

\begin{tabular}{|c|c|c|c|c|c|}
\hline \multirow{2}{*}{$\begin{array}{l}\text { Number } \\
\text { of study } \\
\text { group }\end{array}$} & \multirow{2}{*}{$\begin{array}{c}\text { Business } \\
\text { process } \\
\text { model } \\
\text { label }\end{array}$} & \multicolumn{4}{|c|}{ Complexity } \\
\hline & & $\begin{array}{c}8 \\
\text { Courses }\end{array}$ & $\begin{array}{c}10 \\
\text { Courses }\end{array}$ & $\begin{array}{c}12 \\
\text { Courses }\end{array}$ & $\begin{array}{c}17 \\
\text { Courses }\end{array}$ \\
\hline \multirow{3}{*}{3} & 1 & $1.23 \cdot 10^{2}$ & $2.08 \cdot 10^{2}$ & $2.03 \cdot 10^{4}$ & $1.45 \cdot 10^{6}$ \\
\hline & 2 & $1.02 \cdot 10^{2}$ & $2.33 \cdot 10^{2}$ & $2.03 \cdot 10^{4}$ & $1.50 \cdot 10^{2}$ \\
\hline & 3 & $6.00 \cdot 10^{2}$ & $6.57 \cdot 10^{2}$ & $1.61 \cdot 10^{5}$ & $1.60 \cdot 10^{8}$ \\
\hline \multirow{3}{*}{6} & 1 & $2.98 \cdot 10^{3}$ & $1.14 \cdot 10^{3}$ & $1.61 \cdot 10^{5}$ & $1.92 \cdot 10^{9}$ \\
\hline & 2 & $6.36 \cdot 10^{2}$ & $1.15 \cdot 10^{3}$ & $1.61 \cdot 10^{5}$ & $1.92 \cdot 10^{9}$ \\
\hline & 3 & $6.08 \cdot 10^{2}$ & $6.50 \cdot 10^{2}$ & $1.61 \cdot 10^{5}$ & $1.92 \cdot 10^{9}$ \\
\hline \multirow{3}{*}{9} & 1 & $3.01 \cdot 10^{3}$ & $7.78 \cdot 10^{2}$ & $1.45 \cdot 10^{7}$ & $1.92 \cdot 10^{9}$ \\
\hline & 2 & $3.26 \cdot 10^{2}$ & $6.17 \cdot 10^{2}$ & $1.61 \cdot 10^{5}$ & $8.37 \cdot 10^{13}$ \\
\hline & 3 & $2.99 \cdot 10^{3}$ & $6.40 \cdot 10^{2}$ & $1.61 \cdot 10^{5}$ & $1.92 \cdot 10^{9}$ \\
\hline \multirow{3}{*}{12} & 1 & $1.61 \cdot 10^{5}$ & $6.59 \cdot 10^{2}$ & $1.60 \cdot 10^{8}$ & $1.92 \cdot 10^{9}$ \\
\hline & 2 & $2.03 \cdot 10^{4}$ & $6.20 \cdot 10^{2}$ & $1.92 \cdot 10^{9}$ & $1.60 \cdot 10^{8}$ \\
\hline & 3 & $2.84 \cdot 10^{2}$ & $2.03 \cdot 10^{4}$ & $3.02 \cdot 10^{3}$ & $1.45 \cdot 10^{7}$ \\
\hline \multirow{3}{*}{15} & 1 & $3.46 \cdot 10^{2}$ & $3.33 \cdot 10^{2}$ & $1.45 \cdot 10^{6}$ & $1.92 \cdot 10^{9}$ \\
\hline & 2 & $2.02 \cdot 10^{4}$ & $6.52 \cdot 10^{2}$ & $1.92 \cdot 10^{9}$ & $1.92 \cdot 10^{9}$ \\
\hline & 3 & $1.61 \cdot 10^{5}$ & $1.45 \cdot 10^{6}$ & $1.60 \cdot 10^{8}$ & $1.42 \cdot 10^{15}$ \\
\hline \multirow{3}{*}{18} & 1 & $2.03 \cdot 10^{4}$ & $6.27 \cdot 10^{2}$ & $1.92 \cdot 10^{9}$ & $1.92 \cdot 10^{9}$ \\
\hline & 2 & $1.61 \cdot 10^{5}$ & $1.45 \cdot 10^{7}$ & $1.92 \cdot 10^{9}$ & $1.42 \cdot 10^{15}$ \\
\hline & 3 & $2.03 \cdot 10^{4}$ & $1.45 \cdot 10^{6}$ & $1.92 \cdot 10^{9}$ & $1.42 \cdot 10^{15}$ \\
\hline \multirow{3}{*}{21} & 1 & $6.32 \cdot 10^{2}$ & $1.45 \cdot 10^{7}$ & $3.07 \cdot 10^{3}$ & $1.42 \cdot 10^{15}$ \\
\hline & 2 & $1.61 \cdot 10^{5}$ & $1.45 \cdot 10^{7}$ & $1.92 \cdot 10^{9}$ & $1.42 \cdot 10^{15}$ \\
\hline & 3 & $1.61 \cdot 10^{5}$ & $1.45 \cdot 10^{7}$ & $1.92 \cdot 10^{9}$ & $1.42 \cdot 10^{15}$ \\
\hline \multirow{3}{*}{24} & 1 & $1.61 \cdot 10^{5}$ & $1.45 \cdot 10^{7}$ & $1.92 \cdot 10^{9}$ & $1.42 \cdot 10^{15}$ \\
\hline & 2 & $1.61 \cdot 10^{5}$ & $1.45 \cdot 10^{7}$ & $1.92 \cdot 10^{9}$ & $1.42 \cdot 10^{15}$ \\
\hline & 3 & $1.61 \cdot 10^{5}$ & $1.45 \cdot 10^{7}$ & $1.92 \cdot 10^{9}$ & $1.42 \cdot 10^{15}$ \\
\hline \multirow{3}{*}{27} & 1 & $1.61 \cdot 10^{5}$ & $1.45 \cdot 10^{7}$ & $1.92 \cdot 10^{9}$ & $1.42 \cdot 10^{15}$ \\
\hline & 2 & $1.61 \cdot 10^{5}$ & $1.45 \cdot 10^{7}$ & $1.92 \cdot 10^{9}$ & $1.42 \cdot 10^{15}$ \\
\hline & 3 & $1.61 \cdot 10^{5}$ & $1.45 \cdot 10^{7}$ & $1.92 \cdot 10^{9}$ & $1.42 \cdot 10^{15}$ \\
\hline
\end{tabular}

process from the event $\log$ in Table 3 presented on Fig. 2. Other event logs are processed in a similar way to produce a business process model.
Table 5. Average of business process models complexity

\begin{tabular}{|c|c|c|c|c|}
\hline \multirow{2}{*}{$\begin{array}{c}\text { Number } \\
\text { of study } \\
\text { group }\end{array}$} & \multicolumn{4}{|c|}{ Average of Complexity } \\
\cline { 2 - 5 } & $\begin{array}{c}8 \\
\text { Courses }\end{array}$ & $\begin{array}{c}10 \\
\text { Courses }\end{array}$ & $\begin{array}{c}12 \\
\text { Courses }\end{array}$ & $\begin{array}{c}17 \\
\text { Courses }\end{array}$ \\
\hline 3 & $2.75 \cdot 10^{2}$ & $3.66 \cdot 10^{2}$ & $6.73 \cdot 10^{4}$ & $5.37 \cdot 10^{7}$ \\
\hline 6 & $1.41 \cdot 10^{3}$ & $9.81 \cdot 10^{2}$ & $1.61 \cdot 10^{5}$ & $1.92 \cdot 10^{9}$ \\
\hline 9 & $2.11 \cdot 10^{3}$ & $6.79 \cdot 10^{2}$ & $4.95 \cdot 10^{6}$ & $2.79 \cdot 10^{13}$ \\
\hline 12 & $6.06 \cdot 10^{4}$ & $7.19 \cdot 10^{3}$ & $6.92 \cdot 10^{8}$ & $6.97 \cdot 10^{8}$ \\
\hline 15 & $6.07 \cdot 10^{4}$ & $4.84 \cdot 10^{5}$ & $6.92 \cdot 10^{8}$ & $4.74 \cdot 10^{14}$ \\
\hline 18 & $6.73 \cdot 10^{4}$ & $5.32 \cdot 10^{6}$ & $1.92 \cdot 10^{9}$ & $9.49 \cdot 10^{14}$ \\
\hline 21 & $1.08 \cdot 10^{5}$ & $1.45 \cdot 10^{7}$ & $1.28 \cdot 10^{9}$ & $1.42 \cdot 10^{15}$ \\
\hline 24 & $1.61 \cdot 10^{5}$ & $1.45 \cdot 10^{7}$ & $1.92 \cdot 10^{9}$ & $1.42 \cdot 10^{15}$ \\
\hline 27 & $1.61 \cdot 10^{5}$ & $1.45 \cdot 10^{7}$ & $1.92 \cdot 10^{9}$ & $1.42 \cdot 10^{15}$ \\
\hline
\end{tabular}

\subsection{Calculation of a business process model complexity metric}

The fifth stage calculates the complexity metric of the business process model obtained using the Yaqin Complexity formula on Eq. (1). The results of the Yaqin Complexity calculation are presented in Table 4.

\subsection{Calculation of the average business process model complexity metric}

The sixth stage calculates the average business process model complexity metric for grades 1,2 , and 3 for each study group to obtain nine business process model complexity metrics. The business process model complexity metric needs to be averaged because regression requires only one set of coordinates on the $\mathrm{x}$-axis and the $\mathrm{y}$-axis. The average business process model complexity metric is presented in Table 5 .

3.7 The discovery of the growth function metric for the complexity of the business process model 
The seventh stage regresses the complexity metric of the business process model using logistic regression. The independent variable in this regression is the number of study groups on the $\mathrm{x}$-axis. The regression dependent variable is the complexity metric of the average business process model on the $y$-axis. The logistic regression used in this paper is based on the sigmoid function as in Eq. (2), asymmetric logistic function with 4 parameters as in Eq. (3), and asymmetric logistic function with 5 parameters as in Eq. (4). The discovery of the parameters in these equations was carried out using a calculator available online at https://www.desmos.com. Logistic regression is used because the points on the graph form a pattern that approximates logistical equations.

Apart from using logistic regression, we also use power regression to get the growth function as a function of the number of courses. The discovery of the parameters in these equations was carried out using a calculator available online at https://www.desmos.com.

\section{Results}

\subsection{Experiment results}

Experiments have been carried out with the first case, namely measuring the growth of the business process model complexity for schools that run a curriculum with a varied number of courses, namely $8,10,12$, and 17 . This case is intended to determine the growth of the learning business process model complexity based on the number of study groups. We present the metrics for the complexity of the business process models that have been obtained in Table 5 . Then we regress based on three equations, namely Eqs. (2), (3), and (4). The parameters of the regression results, R2, lower bounds, upper bounds, and bandwidth are presented in Table 6. The upper bound is the farthest data point above the curve line, while the lower bound is the furthest data point below the curve line. Bandwidth is the difference between the upper bound and lower bound. The distribution of points of the business process model complexity forms a curve that approximates the sigmoid equation. The curves are depicted on a chart where the $\mathrm{x}$-axis represents the number of study groups and the y-axis represents the business process model complexity. The business process model complexity growth curves with eight courses are presented in Fig. 3 . The business process model complexity growth curves with ten courses are presented in Fig. 4. The business process model complexity growth curves with 12
Table 6. Result of business process models complexity regression as number of study group function

\begin{tabular}{|c|c|c|c|}
\hline Variable & Equation (2) & Equation (3) & Equation (4) \\
\hline \multicolumn{4}{|c|}{8 Courses } \\
\hline$a$ & & $3.95 \cdot 10^{3}$ & $1.61 \cdot 10^{5}$ \\
\hline$b$ & $-2.69 \cdot 10^{-1}$ & 4.60 & $-3.36 \cdot 10^{2}$ \\
\hline$C$ & $1.07 \cdot 10^{2}$ & 17.2 & 24.6 \\
\hline$d$ & $1.63 \cdot 10^{5}$ & $1.66 \cdot 10^{5}$ & $-3.32 \cdot 10^{3}$ \\
\hline$f$ & & & $6.21 \cdot 10^{-3}$ \\
\hline$R^{2}$ & $9.70 \cdot 10^{-1}$ & $9.63 \cdot 10^{-1}$ & $9.82 \cdot 10^{-1}$ \\
\hline Lower Bound & $-2.12 \cdot 10^{4}$ & $-2.63 \cdot 10^{4}$ & $-1.54 \cdot 10^{4}$ \\
\hline Upper Bound & $2.95 \cdot 10^{4}$ & $3.06 \cdot 10^{4}$ & $2.70 \cdot 10^{4}$ \\
\hline Bandwidth & $5.07 \cdot 10^{4}$ & $5.69 \cdot 10^{4}$ & $4.24 \cdot 10^{4}$ \\
\hline \multicolumn{4}{|c|}{10 Courses } \\
\hline$a$ & & $9.67 \cdot 10^{4}$ & $1.61 \cdot 10^{4}$ \\
\hline$b$ & -1.59 & 37.7 & 15.5 \\
\hline$c$ & $4.73 \cdot 10^{12}$ & 18.3 & 33.8 \\
\hline$d$ & $1.46 \cdot 10^{7}$ & $1.45 \cdot 10^{7}$ & $1.45 \cdot 10^{7}$ \\
\hline$f$ & & & $7.71 \cdot 10^{3}$ \\
\hline$R^{2}$ & 1.00 & 1.00 & 1.00 \\
\hline Lower Bound & $-6.87 \cdot 10^{4}$ & $-9.64 \cdot 10^{4}$ & $-3.27 \cdot 10^{4}$ \\
\hline Upper Bound & $4.13 \cdot 10^{5}$ & $3.79 \cdot 10^{5}$ & $7.92 \cdot 10^{4}$ \\
\hline Bandwidth & $4.82 \cdot 10^{5}$ & $4.75 \cdot 10^{5}$ & $1.12 \cdot 10^{5}$ \\
\hline \multicolumn{4}{|c|}{12 Courses } \\
\hline$a$ & & $-2.31 \cdot 10^{7}$ & $-2.89 \cdot 10^{7}$ \\
\hline$b$ & $-4.36 \cdot 10^{-1}$ & 5.38 & 5.01 \\
\hline$c$ & $5.83 \cdot 10^{2}$ & 14.6 & 15.5 \\
\hline$d$ & $1.84 \cdot 10^{9}$ & $1.93 \cdot 10^{9}$ & $1.92 \cdot 10^{9}$ \\
\hline$f$ & & & 1.24 \\
\hline$R^{2}$ & $9.00 \cdot 10^{-1}$ & $9.46 \cdot 10^{-1}$ & $9.46 \cdot 10^{-1}$ \\
\hline Lower Bound & $-4.51 \cdot 10^{8}$ & $-4.10 \cdot 10^{8}$ & $-4.18 \cdot 10^{8}$ \\
\hline Upper Bound & $4.22 \cdot 10^{8}$ & $4.63 \cdot 10^{8}$ & $4.64 \cdot 10^{8}$ \\
\hline Bandwidth & $8.73 \cdot 10^{8}$ & $8.73 \cdot 10^{8}$ & $8.73 \cdot 10^{8}$ \\
\hline \multicolumn{4}{|c|}{17 Courses } \\
\hline$a$ & & $1.47 \cdot 10^{15}$ & $-1.16 \cdot 10^{13}$ \\
\hline$b$ & $-5.94 \cdot 10^{-1}$ & -9.48 & 6.82 \\
\hline$c$ & $1.90 \cdot 10^{4}$ & 16.5 & 90.7 \\
\hline$d$ & $1.45 \cdot 10^{15}$ & $-4.53 \cdot 10^{12}$ & $1.43 \cdot 10^{15}$ \\
\hline$f$ & & & $7.32 \cdot 10^{4}$ \\
\hline$R^{2}$ & $9.94 \cdot 10^{-1}$ & $9.94 \cdot 10^{-1}$ & $9.95 \cdot 10^{-1}$ \\
\hline Lower Bound & $-8.89 \cdot 10^{13}$ & $-7.19 \cdot 10^{13}$ & $-9.16 \cdot 10^{13}$ \\
\hline Upper Bound & $7.06 \cdot 10^{13}$ & $8.78 \cdot 10^{13}$ & $6.96 \cdot 10^{13}$ \\
\hline Bandwidth & $1.59 \cdot 10^{14}$ & $1.60 \cdot 10^{14}$ & $1.59 \cdot 10^{14}$ \\
\hline
\end{tabular}

courses are presented in Fig. 5. The business process model complexity growth curves with 17 courses are presented in Fig. 6.

Next, we perform a regression based on the power function for the data on Table 5. We use this power function to find the growth function for the complexity of the business process model as a function of the number of courses. The parameters of the regression results, $\mathrm{R}^{2}$, lower bounds, and upper bounds are presented in Table 7 , and the curves are presented in Fig. 7. The points distribution of the 


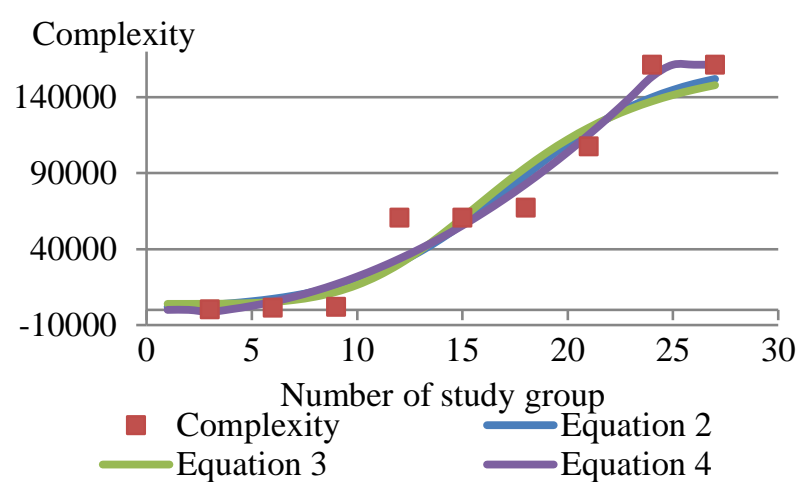

Figure. 3 Chart of 8 courses business process models complexity regression as number of study group function

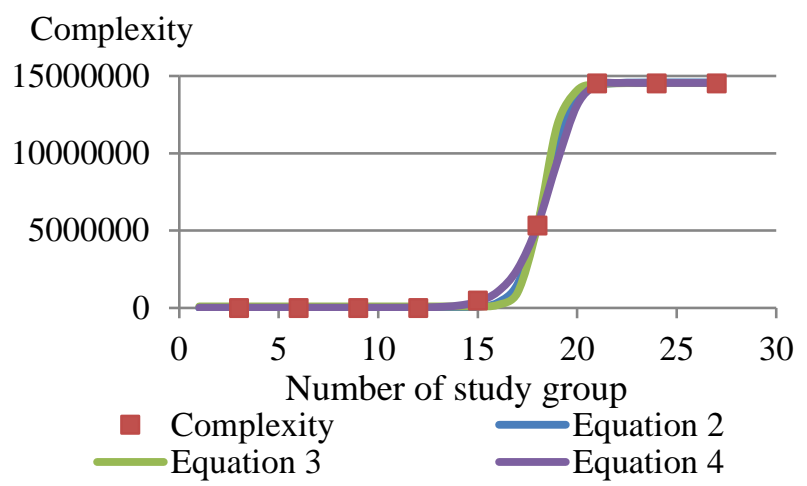

Figure. 4 Chart of 10 courses business process models complexity regression as number of study group function

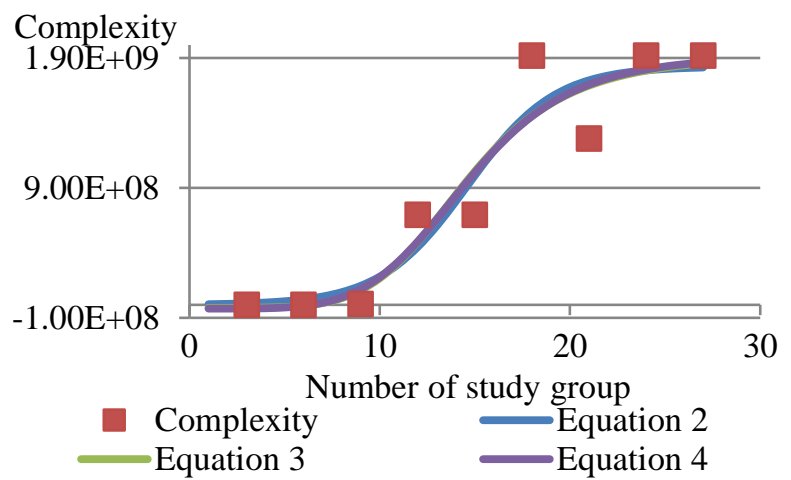

Figure. 5 Chart of 12 courses business process models complexity regression as number of study group function

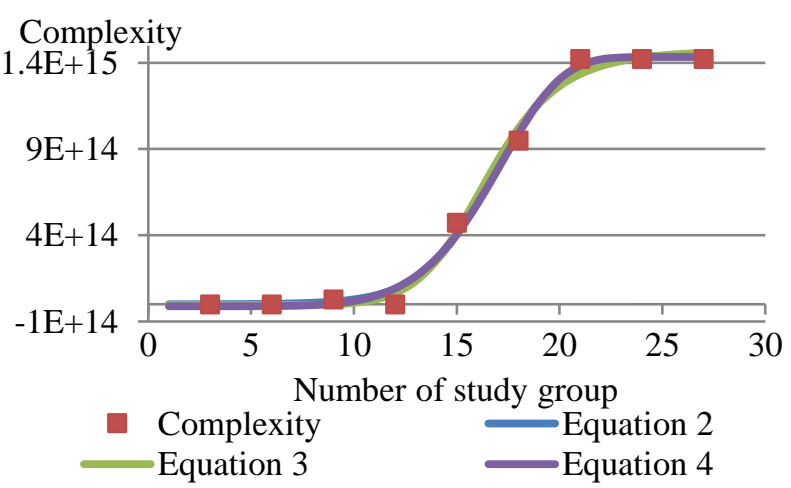

Figure. 6 Chart of 17 courses business process models complexity regression as number of study group function business process model complexity forms a curve that approximates the power equation. The curves are drawn on a chart where the $\mathrm{x}$-axis represents the number of courses and the $y$-axis represents the complexity of the business process model.

In the second case, we normalize the average value of the business process model complexity so that it can be compared and analyzed. The results of normalization are presented in Table 8 . Then we regress it based on Eqs. (2), (3), and (4). Regression curves based on Eq. (2) are presented in Fig. 8.

Table 7 Result of business process models complexity regression as number of courses function

\begin{tabular}{|c|c|c|c|c|c|}
\hline \multirow{2}{*}{$\begin{array}{c}\text { Number } \\
\text { of study } \\
\text { group }\end{array}$} & \multicolumn{2}{|c|}{ Parameters } & \multirow[b]{2}{*}{$R^{2}$} & \multirow{2}{*}{$\begin{array}{l}\text { Lower } \\
\text { bound }\end{array}$} & \multirow{2}{*}{$\begin{array}{l}\text { Upper } \\
\text { bound }\end{array}$} \\
\hline & $g$ & $h$ & & & \\
\hline 3 & $1.33 \cdot 10^{-16}$ & 19.186 & 1 & $-5.09 \cdot 10^{3}$ & $2.47 \cdot 10^{2}$ \\
\hline 6 & $1.38 \cdot 10^{-24}$ & 26.9344 & 1 & $-7.49 \cdot 10^{4}$ & $1.41 \cdot 10^{3}$ \\
\hline 9 & $3.38 \cdot 10^{-42}$ & 44.6316 & 1 & $-7.21 \cdot 10^{8}$ & $2.11 \cdot 10^{3}$ \\
\hline 12 & $1.21 \cdot 10^{6}$ & 2.27393 & 0.5948 & $-2.28 \cdot 10^{8}$ & $3.47 \cdot 10^{8}$ \\
\hline 15 & $1.61 \cdot 10^{-33}$ & 38.5784 & 1 & $-1.26 \cdot 10^{5}$ & $3.00 \cdot 10^{10}$ \\
\hline 18 & $4.52 \cdot 10^{-32}$ & 37.6461 & 1 & $-5.29 \cdot 10^{3}$ & $\cdot 10^{6}$ \\
\hline 21 & $9.26 \cdot 10^{-35}$ & 39.9743 & 1 & -4. & $10^{7}$ \\
\hline 24 & $2.51 \cdot 10^{-33}$ & 38.8102 & 1 & $-3.89 \cdot 10^{10}$ & $\cdot 10^{7}$ \\
\hline 27 & $2.51 \cdot 10^{-33}$ & 38.8102 & 1 & $-3.89 \cdot 10^{10}$ & $1.29 \cdot 10^{7}$ \\
\hline & Average & & 0.9549 & & \\
\hline
\end{tabular}

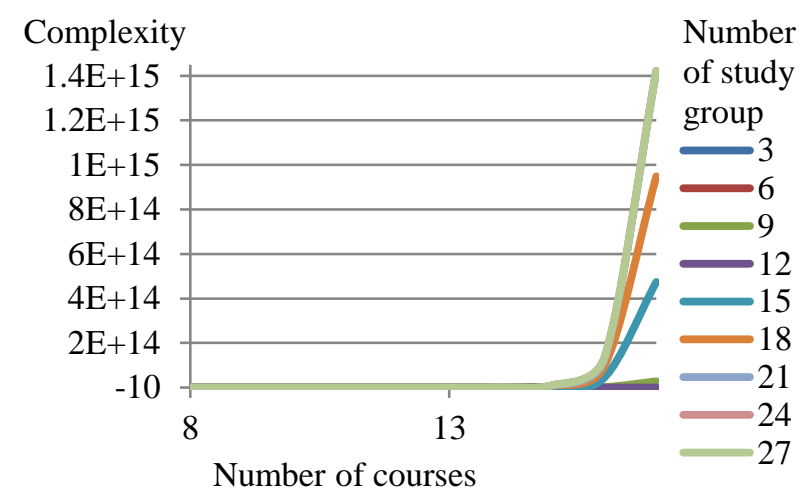

Figure. 7 Chart of business process models complexity regression as number of courses function

Table 8. Normalization of business process models complexity average

\begin{tabular}{|c|c|c|c|c|}
\hline \multirow{2}{*}{$\begin{array}{c}\text { Number } \\
\text { of study } \\
\text { group }\end{array}$} & \multicolumn{4}{|c|}{ Average of Complexity } \\
\cline { 2 - 5 } & 8 Courses & $\begin{array}{c}10 \\
\text { Courses }\end{array}$ & $\begin{array}{c}12 \\
\text { Courses }\end{array}$ & $\begin{array}{c}17 \\
\text { Courses }\end{array}$ \\
\hline 3 & $1.70 \cdot 10^{-3}$ & $2.52 \cdot 10^{-5}$ & $3.51 \cdot 10^{-5}$ & $3.77 \cdot 10^{-8}$ \\
\hline 6 & $8.73 \cdot 10^{-3}$ & $6.76 \cdot 10^{-5}$ & $8.43 \cdot 10^{-5}$ & $1.35 \cdot 10^{-6}$ \\
\hline 9 & $1.31 \cdot 10^{-2}$ & $4.68 \cdot 10^{-5}$ & $2.58 \cdot 10^{-3}$ & $1.96 \cdot 10^{-2}$ \\
\hline 12 & $3.76 \cdot 10^{-1}$ & $4.96 \cdot 10^{-4}$ & $3.61 \cdot 10^{-1}$ & $4.90 \cdot 10^{-7}$ \\
\hline 15 & $3.76 \cdot 10^{-1}$ & $3.34 \cdot 10^{-2}$ & $3.61 \cdot 10^{-1}$ & $3.33 \cdot 10^{-1}$ \\
\hline 18 & $4.17 \cdot 10^{-1}$ & $3.67 \cdot 10^{-1}$ & 1.00 & $6.67 \cdot 10^{-1}$ \\
\hline 21 & $6.68 \cdot 10^{-1}$ & 1.00 & $6.67 \cdot 10^{-1}$ & 1.00 \\
\hline 24 & 1.00 & 1.00 & 1.00 & 1.00 \\
\hline 27 & 1.00 & 1.00 & 1.00 & 1.00 \\
\hline
\end{tabular}


Table 9 Result of regression of business process models complexity as number of study group function normalization

\begin{tabular}{|c|c|c|c|}
\hline Variable & Equation (2) & Equation (3) & Equation (4) \\
\hline \multicolumn{4}{|c|}{8 Courses } \\
\hline$a$ & & $2.45 \cdot 10^{-2}$ & 1.00 \\
\hline$b$ & $-2.69 \cdot 10^{-1}$ & 4.60 & $-3.36 \cdot 10^{2}$ \\
\hline c & $1.07 \cdot 10^{2}$ & 17.2 & 24.6 \\
\hline$d$ & 1.01 & 1.03 & $-2.06 \cdot 10^{-2}$ \\
\hline$f$ & & & $6.21 \cdot 10^{-3}$ \\
\hline$R^{2}$ & $9.70 \cdot 10^{-1}$ & $9.63 \cdot 10^{-1}$ & $9.82 \cdot 10^{-1}$ \\
\hline Lower Bound & $-1.31 \cdot 10^{-1}$ & $-1.63 \cdot 10^{-1}$ & $-9.54 \cdot 10^{-2}$ \\
\hline Upper Bound & $1.83 \cdot 10^{-1}$ & $1.89 \cdot 10^{-1}$ & $1.68 \cdot 10^{-1}$ \\
\hline Bandwidth & $3.14 \cdot 10^{-1}$ & $3.53 \cdot 10^{-1}$ & $2.63 \cdot 10^{-1}$ \\
\hline \multicolumn{4}{|c|}{10 Courses } \\
\hline$a$ & & $6.66 \cdot 10^{-3}$ & 1.00 \\
\hline$b$ & -1.59 & 37.7 & $-1.31 \cdot 10^{2}$ \\
\hline$c$ & $4.73 \cdot 10^{12}$ & 18.3 & 19.4 \\
\hline$d$ & 1.00 & 1.00 & $-2.70 \cdot 10^{-4}$ \\
\hline$f$ & & & $1.01 \cdot 10^{-1}$ \\
\hline$R^{2}$ & 1.00 & 1.00 & 1.00 \\
\hline Lower Bound & $-4.73 \cdot 10^{-3}$ & $-6.64 \cdot 10^{-3}$ & $-1.02 \cdot 10^{-3}$ \\
\hline Upper Bound & $2.85 \cdot 10^{-2}$ & $2.61 \mathrm{E} \cdot 10^{-2}$ & $3.38 \cdot 10^{-4}$ \\
\hline Bandwidth & $3.32 \mathrm{E}-02$ & $3.27 \mathrm{E}-02$ & $1.36 \mathrm{E}-03$ \\
\hline \multicolumn{4}{|c|}{12 Courses } \\
\hline$a$ & & 1.02 & $5.95 \cdot 10^{-5}$ \\
\hline$b$ & $-4.36 \cdot 10^{-1}$ & -5.10 & 59.6 \\
\hline$c$ & $5.83 \cdot 10^{2}$ & 14.7 & 9.33 \\
\hline$d$ & $9.58 \cdot 10^{-1}$ & $-1.58 \cdot 10^{-2}$ & 1.88 \\
\hline$f$ & & & $1.23 \cdot 10^{-2}$ \\
\hline$R^{2}$ & $9.44 \cdot 10^{-1}$ & $9.46 \cdot 10^{-1}$ & $9.46 \cdot 10^{-1}$ \\
\hline Lower Bound & $-2.35 \cdot 10^{-1}$ & $-2.14 \cdot 10^{-1}$ & $-1.91 \cdot 10^{-1}$ \\
\hline Upper Bound & $2.20 \cdot 10^{-1}$ & $2.47 \cdot 10^{-1}$ & $2.81 \cdot 10^{-1}$ \\
\hline Bandwidth & $4.56 \cdot 10^{-1}$ & $4.61 \cdot 10^{-1}$ & $4.72 \cdot 10^{-1}$ \\
\hline \multicolumn{4}{|c|}{17 Courses } \\
\hline$a$ & & $-3.19 \cdot 10^{-3}$ & $-8.18 \cdot 10^{-3}$ \\
\hline$b$ & $-5.94 \cdot 10^{-1}$ & 9.48 & 6.82 \\
\hline$c$ & $1.90 \cdot 10^{4}$ & 16.5 & 54.2 \\
\hline$d$ & 1.02 & 1.03 & 1.01 \\
\hline$f$ & & & $2.18 \cdot 10^{3}$ \\
\hline$R^{2}$ & $9.94 \cdot 10^{-1}$ & $9.94 \cdot 10^{-1}$ & $9.95 \cdot 10^{-1}$ \\
\hline Lower Bound & $-6.25 \cdot 10^{-2}$ & $-5.05 \cdot 10^{-2}$ & $-6.44 \cdot 10^{-2}$ \\
\hline Upper Bound & $4.96 \cdot 10^{-2}$ & $6.17 \cdot 10^{-2}$ & $4.89 \cdot 10^{-2}$ \\
\hline Bandwidth & $1.12 \cdot 10^{-1}$ & $1.12 \cdot 10^{-1}$ & $1.13 \cdot 10^{-1}$ \\
\hline
\end{tabular}

Regression curves based on Eq. (3) are presented in Fig. 9. Regression curves based on Eq. (4) are presented in Fig. 10.

In second case, we also regress based on Eq. (5). The regression results curves are presented in Table 10 as shown in Fig. 11.

\section{Discussion}

\subsection{Discussion of experimental results}

Normalization

Complexity

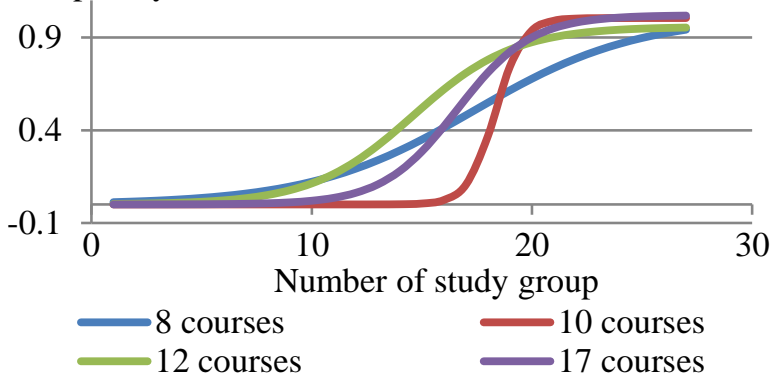

Figure. 8 Regression curve comparison based on equation 2

Normalization

Complexity

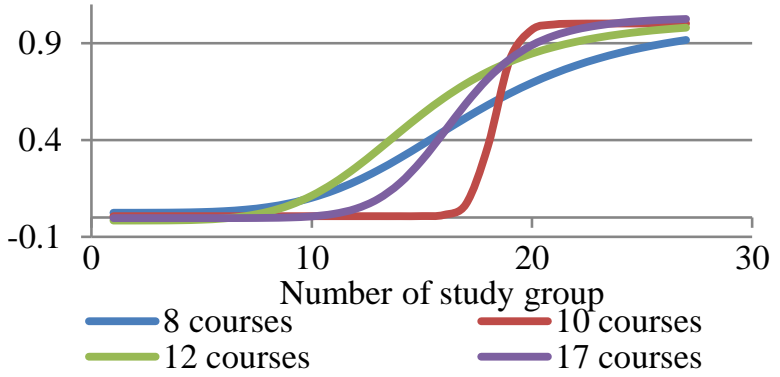

Figure 9 Regression curve comparison based on equation 3

Normalization

Complexity

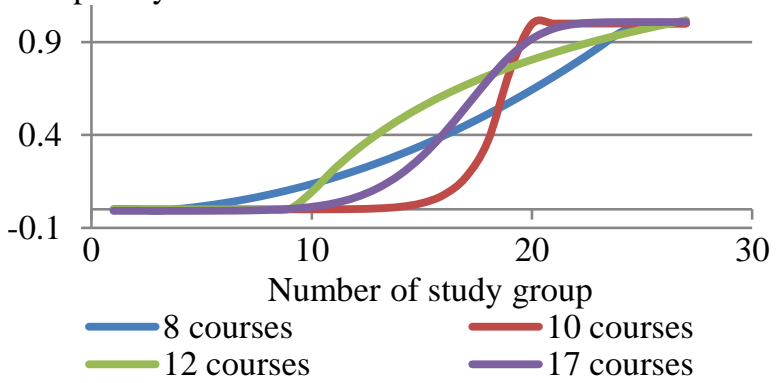

Figure 10 Regression curve comparison based on equation 4

Table 10 Result of business process models complexity regression as number of courses function normalization

\begin{tabular}{|c|c|c|c|c|c|}
\hline \multirow{2}{*}{$\begin{array}{c}\text { Number } \\
\text { of study } \\
\text { group }\end{array}$} & $g$ & $h$ & $R^{2}$ & $\begin{array}{c}\text { Lower } \\
\text { bound }\end{array}$ & $\begin{array}{c}\text { Upper } \\
\text { bound }\end{array}$ \\
\cline { 2 - 5 } 3 & $2.47 \cdot 10^{-24}$ & 19.186 & 1 & $-3.11 \cdot 10^{-5}$ & $4.59 \cdot 10^{-6}$ \\
\hline 6 & $7.22 \cdot 10^{-34}$ & 26.9344 & 1 & $-1.09 \cdot 10^{-7}$ & $7.34 \cdot 10^{-7}$ \\
\hline 9 & $1.21 \cdot 10^{-55}$ & 44.6316 & 1 & $-2.75 \cdot 10^{-11}$ & $7.57 \cdot 10^{-11}$ \\
\hline 12 & $1.74 \cdot 10^{-3}$ & 2.27393 & 0.5948 & $-2.99 \cdot 10^{-1}$ & $5.40 \cdot 10^{-1}$ \\
\hline 15 & $3.40 \cdot 10^{-48}$ & 38.5784 & 1 & $-2.66 \cdot 10^{-10}$ & $1.28 \cdot 10^{-10}$ \\
\hline 18 & $4.77 \cdot 10^{-47}$ & 37.6461 & 1 & $-1.18 \cdot 10^{-11}$ & $3.50 \cdot 10^{-9}$ \\
\hline 21 & $6.51 \cdot 10^{-50}$ & 39.9743 & 1 & $-6.21 \cdot 10^{-12}$ & $9.59 \cdot 10^{-9}$ \\
\hline 24 & $1.76 \cdot 10^{-48}$ & 38.8102 & 1 & $-9.06 \cdot 10^{-9}$ & $8.67 \cdot 10^{-12}$ \\
\hline 27 & $1.76 \cdot 10^{-48}$ & 38.8102 & 1 & $-8.67 \cdot 10^{-12}$ & $9.06 \cdot 10^{-9}$ \\
\hline
\end{tabular}




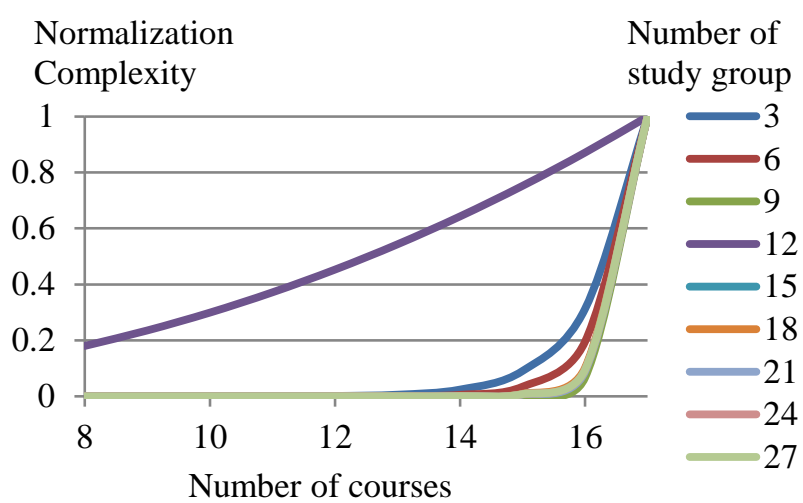

Figure. 11 Chart of business process models complexity regression as number of course function normalization

In this section, we discuss some of our findings, namely:

- Courses scheduled once a week do not form a loop, while courses scheduled more than once form a loop. The formation of loops increases the complexity of the business process model.

- The schedule for each study group is a case in process mining. The complexity of the business process model increases along with the number of cases involved in the mining process. When it reaches a certain number of cases, the business process model shape will no longer change even if the number of cases is increased. The distribution of the business process model complexity to the number of cases forms a sigmoid curve as shown in Fig. 3, Fig. 4, Fig. 5, and Fig. 6.

- In this study, the most significant increase in the complexity of the business process model is when the number of branches in the AND branch increases due to the increasing number of cases involved in the mining process.

- Our experiment observes the growing complexity of the business process model based on the number of study groups in the first case. The data distribution of the business process model complexity forms a pattern that is close to the sigmoid equation. Therefore, we choose the sigmoid equation as the basic equation for measuring the business process growth complexity. The sigmoid equation is proven to be very good in approaching the data distribution of the business process model complexity with a value of $R^{2}>0.9$. There are three types of sigmoid equations that we have tried, namely the logistic regression equation that uses 3 parameters, 4 parameters, and 5 parameters. The regression results are presented in Table 6 . The best regression results with the highest average $R^{2}$ value is 0.9698 in Eq. (4). In addition to $\mathrm{R}^{2}$, lower bound and upper bound are obtained from each sigmoid equation presented in Table 6 . The greater the number of subjects, the greater the difference between the upper bound and lower bound data distribution of the complexity of the business process model metric because the complexity metric of the business process model is also increasing. This is related to process mining, therefore the addition the number of cases in the discovery of business process models results in the growth of its complexity following the sigmoid equation.

- Next, we observe the growth of the business process model complexity based on the number of courses. The data distribution on the complexity of the business process model forms a close to the power equation. Therefore, we chose the power equation as the basic equation for measuring the business process model growth. The power equation also proved to be very good in approaching the data distribution of the business process model complexity with an average value of $R^{2}=0.9549$. The regression results are presented in Table 7. In addition to R2, lower bound and upper bound are obtained from each power equation presented in Table 7 . The more the number of study groups, the difference between the upper bound and lower bound data distribution of the complexity of the business process model metric tends to be more significant because the complexity metric of the business process model is also getting more significant. This is related to process mining, therefore the increase in the number of activities in the business process model results in a growth in complexity following the power equation as formulated in Eq. (5).

- In the second case, we compare the effect of variation in the number of courses on the business process model growth in complexity. In the second case, we normalize the average value for the complexity of the business process model. We perform normalization to get the same scale on each curve so that the shape and equation of the regression results can be compared and analyzed.

- The curve obtained is based on Eq. (2) which is presented in Figure. 8, which shows that the growth of the business process model in 8 courses has the smoothest curve and is the closest to linear; this is represented by the value of the variable $b$, which is greater than the other curves. While the most vertical curve is the growth curve of the 10 courses business process model, but this 
curve has the largest inflection point among the other curves.

- Based on the business process model complexity growth curve presented in Fig. 8, Fig. 9, and Fig. 10 , it is found that the growth curve for the complexity of the business process model as a function of the number of study groups has no predictable pattern. Likewise, the business process model complexity growth curve represents the growth function as a function of the number of courses. The business process model growth curve is highly dependent on the schedule generated in the scheduling process.

- In this second case, we observe the distribution of the business process model complexity metric data on the normalized function of the number of study groups. Based on the data distribution of the complexity of the business process model, we get the lower bound and upper bound which are presented in Table 9. Our observations found that the smallest bandwidth for 8 and 10 courses was found in Eq. (4), namely 0.2630 and 0.0014 . While for 12 and 17 courses, the smallest bandwidth is found in Eq. (2), namely 0.4556 and 0.1121 . These bandwidth values indicate that $\mathrm{Eq}$. (4) is best suited to represent growth as a function of the number of study groups for 8 and 10 courses, while Eq. (2) is best suited to represent growth as a function of the number of study groups for 12 and 17 courses.

- Next, we observe the distribution of the business process model complexity metric data on the normalized function of the number of courses. Based on the data distribution of the complexity of the business process model, we get the lower bound and upper bound which are presented in Table 10. Our observations found that the average bandwidth is minimal, namely 0.0933 . This bandwidth value indicates that the regression based on the power equation in Eq. (5) is suitable for representing the growth in the complexity of the business process model as a function of the number of courses.

\section{Conclusion}

Based on the discussion above, we can conclude that:

1. The equation for the growth of the complexity of the business process model as a function of the study groups number is obtained through 3 parameters, 4 parameters, and 5 parameters logistic regression.
2. Generally, the best equation to represent the growth in complexity of the business process model as a function of the number of study groups is the sigmoid equation with 5 parameters with a value of $R^{2}=0.9698$.

3. In more detail, the asymmetric sigmoid equation with 5 parameters is most suitable to represent the growth in the complexity of the business process model as a function of the number of study groups for 8 and 10 courses because it has the slightest bandwidth. Meanwhile, for 12 and 17 subjects, the growth in complexity of the business process model is represented by a sigmoid equation with 3 parameters.

4. The equation for the growth of the complexity of the business process model as a function of the courses number is obtained through power regression with an average value of $R^{2}=0.9549$ and the bandwidth averages $=0.0933$.

5. The growth curve of the complexity of the business process model as a function of the number of study groups and as a function of the number of courses does not have a specific growth pattern. The growth curve is highly dependent on the results of the course schedule.

In addition to some of the results above, this research also still needs some improvements, namely:

1. The business process model complexity growth equation in this study is influenced by the number of courses and study groups. However, they are still separated in different equations. Therefore it is necessary to have research to combine the number of courses and the number of study groups in one equation.

2. This research is limited to case studies of the implementation of learning in schools so that further research is needed to apply it to other cases.

3. The results of this study are part of measuring enterprise architecture growth, especially in estimating information systems configuration based on business architecture complexity.

\section{Conflicts of interest}

The authors (Muhammad Ainul Yaqin, Riyanarto Sarno, Siti Rochimah) declare no conflict of interest. 


\section{Author contributions}

Conceptualization, Muhammad Ainul Yaqin; Methodology, Muhammad Ainul Yaqin; Validation, Muhammad Ainul Yaqin; Formal analysis, Muhammad Ainul Yaqin; Investigation, Muhammad Ainul Yaqin; Resources, Muhammad Ainul Yaqin; Data curation, Muhammad Ainul Yaqin; Writingoriginal draft preparation, Muhammad Ainul Yaqin; Writing - review and editing, Riyanarto Sarno and Siti Rochimah; Visualization, Muhammad Ainul Yaqin; Supervision, Riyanarto Sarno and Siti Rochimah.

\section{References}

[1] P. R. Indonesia, Undang-undang Republik Indonesia Nomor 2 Tahun 1989, 1989, Sistem Pendidikan Nasional.

[2] K. M. Nassar and M. Y Hegab, "Developing a Complexity Measure for Project Schedules", Journal of Construction Engineering and Management, Vol. 132, No. 6, pp. 554-561, 2006.

[3] S Morcov, L Pintelon, and R. J Kusters, "Definitions, characteristics and measures of IT project complexity-a systematic literature review", International Journal of Information Systems and Project Management, Vol. 8, No. 2, pp. 5-21, 2020.

[4] M. A. Yaqin, R. Sarno, and S. Rochimah, "Measuring Scalable Business Process Model Complexity Based on Basic Control Structure", International Journal of Intelligence Engineering \& Systems, Vol. 13, No. 6, pp. 5265, 2020.

[5] M. A. Yaqin, R. Sarno, and A. C. Fauzan, "Scalability Measurement of Business Process Model using Business Processes Similarity and Complexity", In: Proc. of 4th International Conference on Electrical Engineering, Computer Science and Informatics (EECSI), 2017, pp. 1-7, 2017.

[6] L. G. Weinzimmer, P. C. Nystrom, and S. J. Freeman, "Measuring Organizational Growth: Issues, Consequences and Guidelines", Journal of Management, Vol. 24, No. 2, pp. 235-262, 1998.

[7] S. Adomako and K. F. Mole, "Small Business Growth and Performance", The SAGE Handbook of Small Business and Entrepreneurship, R Blackburn, D De Clercq, and J Heinonen, Eds.: Sage, 2018.

[8] R. Vaz, "Firm Growth: A review of the empirical literature", Revista Galega de
Economia, Vol. 30, No. 2, pp. 1-20, 2021.

[9] M. J. Panik, Growth Curve Modeling: Theory and Applications.: John Wiley \& Sons, 2014.

[10] C. U. Press, Cambridge Dictionary. [Online]. https://dictionary.cambridge.org/dictionary/engl ish/schedule

[11] A Wren, "Scheduling, timetabling and rostering - a special relationship?", In: Proc. of International conference on the practice and theory of automated timetabling, 1995, pp. 4675.

[12] A. Schaerf, "A Survey of Automated Timetabling", Artificial Intelligence Review, Vol. 13, No. 2, pp. 87-127, 1999.

[13] J. S. Tan, S. L. Goh, G. Kendall, and N. R. Sabar, "A survey of the state-of-the-art of optimisation methodologies in school timetabling problems", Expert Systems with Applications, Vol. 165, p. 113943, March 2021.

[14] A. A. S. Consultants. (July, 2013) What Algorithm do You Use in Your Generator? [Online].

https://help.asctimetables.com/text.php?id=803 \&lang=en\#: :text=What\%20algorithm\%20do\% 20 you $\% 20$ use,per\%20physical\%20core\%20of $\% 20 \mathrm{CPU})$

[15] A. A. Kalenkova, W. M. P. V. D. Aalst, I. A. Lomazova, and V. A. Rubin, "Process Mining Using BPMN: Relating Event Logs and Process Models", Software \& Systems Modeling, Vol. 16, No. 4, pp. 1019-1048, 2017.

[16] D. Dakic, D. Stefanovic, T. Lolic, D. Narandzic, and N. Simeunovic, "Event Log Extraction for The Purpose of Process Mining: A Systematic Literature Review", In: Proc. of International Symposium in Management Innovation for Sustainable Management and Entrepreneurship, pp. 299-312, 2019.

[17] W. M. P. V. D. Aalst, Data Science in Action, 2nd ed.: Springer, 2016.

[18] S. Agostinelli, F. M. Maggi, A. Marrella, and F. Milani, "A User Evaluation of Process Discovery Algorithms in a Software Engineering Company", In: Proc. of 2019 IEEE 23rd International Enterprise Distributed Object Computing Conference (EDOC), pp. 142-150, 2019.

[19] R. Sarno and K. R. Sungkono, "A Survey of Graph-based Algorithms for Discovering Business Processes", International Journal of Advances in Intelligent Informatics, Vol. 5, No. 2, pp. 137-149, 2019.

[20] S. J. J. Leemans, D. Fahland, and W. M. P. V. D. Aalst, "Discovering Block-structured Process Models from Event Logs-a Constructive 
Approach", In: Proc. of International Conference on Applications and Theory of Petri nets and Concurrency, pp. 311-329, 2013.

[21] K. B. Lassen and W. M. P. V. D. Aalst, "Complexity Metrics for Workflow Nets", Information and Software Technology, Vol. 51, No. 3, pp. 610-626, 2009.

[22] A. Dmitrienko, C. C. Stein, and R. B. D. Agostino Sr, Pharmaceutical Statistics Using SAS: a Practical Guide, 1st ed.: SAS Institute, 2007.

[23] V. Sit and M. P. Costello, Catalogue of Curves for Curve Fitting.: Citeseer, 1994. 